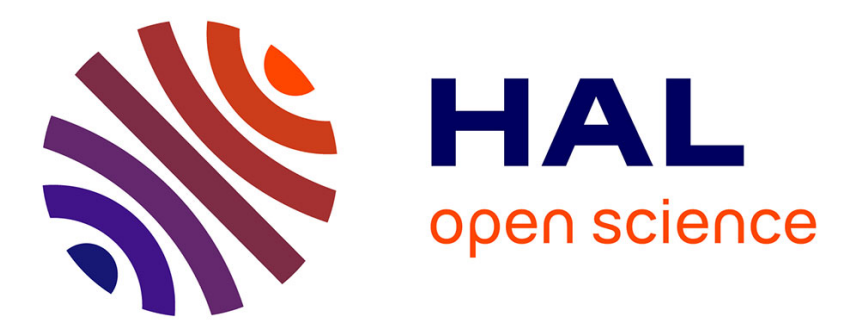

\title{
Social Psychology and Neuroscience: Strange Bedfellows or a Healthy Marriage?
}

\author{
John F. Dovidio, Adam R. Pearson, Patrick Orr
}

\section{To cite this version:}

John F. Dovidio, Adam R. Pearson, Patrick Orr. Social Psychology and Neuroscience: Strange Bedfellows or a Healthy Marriage?. Group Processes and Intergroup Relations, 2008, 11 (2), pp.247263. 10.1177/1368430207088041 . hal-00571686

\section{HAL Id: hal-00571686 https://hal.science/hal-00571686}

Submitted on 1 Mar 2011

HAL is a multi-disciplinary open access archive for the deposit and dissemination of scientific research documents, whether they are published or not. The documents may come from teaching and research institutions in France or abroad, or from public or private research centers.
L'archive ouverte pluridisciplinaire HAL, est destinée au dépôt et à la diffusion de documents scientifiques de niveau recherche, publiés ou non, émanant des établissements d'enseignement et de recherche français ou étrangers, des laboratoires publics ou privés. 


\title{
Social Psychology and Neuroscience: Strange Bedfellows or a Healthy Marriage?
}

\author{
John F. Dovidio, Adam R. Pearson and Patrick Orr \\ Yale University
}

\begin{abstract}
In this paper, we assess what neuroscience theory and method have contributed to the study of group processes and intergroup relations and what we see as potential future contributions to the discipline. We briefly review the historical relation between neuroscience and social psychology, identify issues that may limit the value of neuroscience to the study of group processes and relations, and then argue that social neuroscience indeed holds significant promise for understanding many key elements of group processes and intergroup relations. Both the potential problems and the potential benefits of bridging neuroscience and social psychology are considered in terms of theoretical considerations, empirical issues, and practical implications. We conclude that, although not all group phenomena may be reducible to neural activity and pathways, there are significant benefits to social psychology by having an even broader multidisciplinary orientation within social psychology, one that incorporates the complementary perspectives, techniques, and knowledge of neuroscience.
\end{abstract}

KEYWORDS emotion, implicit attitudes, intergroup relations, neuroimaging, prejudice, racism, social neuroscience

Social neuroscience, as this Special Issue of GPIR attests, is clearly one of the 'hot' areas of interest in social psychology today. In 2002, John Cacioppo and 11 co-editors published a seminal volume, Foundations of Social Neuroscience. In 2003, the Attitudes and Social Cognition section of the Journal of Personality and Social Psychology, a premier journal in social psychology, had a 'special section' on social neuroscience. The value of bridging social psychology and neuroscience was similarly recognized by neuroscientists. In 2003, Neuropsychologia dedicated a special issue to 'The Cognitive Neuroscience of Social Behavior,' in 2004 the Journal of Cognitive Neuroscience sponsored a special issue on social cognitive neuroscience. In recent years, several psychology departments have incorporated 'brain sciences' into their designations. Also, work in social neuroscience has garnered an increasing share of federal grant budgets in recent years, and interest in the field has spawned new journals, such as Social Cognitive and Affective

\footnotetext{
$\overline{\text { Author's note }}$

Address correspondence to John F. Dovidio, Department of Psychology, Yale University, 2 Hillhouse Ave., P.O. Box 208205, New Haven, CT 06520, USA [email: john.dovidio@yale.edu]
} 
Neuroscience and Social Neuroscience (both first published in 2006).

There is general consensus that the integration of neuroscience and social psychology holds unique promise. Heatherton (2004), in his introduction to the special issue on social cognitive neuroscience in the Journal of Cognitive Neuroscience wrote, 'The neuroscientific study of social cognition reflects a new interdisciplinary and dynamic approach that is providing crucial insights into longstanding social psychological questions' (p. 1681). The scholarly momentum of recent years appears to indicate a new era of exceptional potential and excitement.

However, progress in integrating neuroscience into mainstream social psychology has been notably slow. Even with special issues of journals, the number of published studies in primary social psychology outlets (e.g. Journal of Personality and Social Psychology, Personality and Social Psychology Bulletin, Journal of Experimental Social Psychology, and other more specialized journals, such as Group Processes and Intergroup Relations and Social Cognition) incorporating neuroimaging data, particularly those using functional magnetic resonance imaging (fMRI) or event related potential techniques, have rarely exceeded a half dozen in a single year.

Some reasons for their slow integration may relate simply to practical considerations associated with the editorial process itself. In social psychology, the initial review process takes three months or more, several rounds of revision may be required, and publication lags are frequently over a year long. In a rapidly developing field, such as social neuroscience, timeliness of communication is critical, and neuroscience journals may often pose as more attractive outlets for those concerned about expediency in the dissemination of their work. In addition, the bias toward more programmatic research within some mainstream social psychology outlets, encouraging multiple instantiations of processes and theory, may often discourage researchers from pursuing more resource-intensive neuroscience methods. However, other reasons for the paucity of social neuroscience papers in mainstream social psychology journals may relate to more substantive scientific issues, such as traditionally differing interests and foci of neuroscientists and social psychologists in more descriptive (e.g. functional characterization of neural processes) and theory-driven approaches.

In this article, we explore some potential reasons for the estrangement of neuroscience and social psychology, in our assessment both justified and unjustified, and examine the relationship between neuroscience and social psychology from a social psychological perspective. Specifically, we assess what neuroscience theory and method have contributed to the study of group processes and intergroup relations and what we see as potential future contributions to the discipline. Our perspective is admittedly, and intentionally, a social psychological one. That is, even while recognizing the potential benefits of understanding social psychological theories and problems for neuroscience, the question we ask is whether and how neuroscience benefits social psychology, in general, and the study of group and intergroup processes in particular.

Our analysis is not intended to be encyclopedic or fully definitive. Our goal is to stimulate thought and discussion, and we make a limited number of points with specific illustrative examples. We first briefly review the historical relation between neuroscience and social psychology. We next identify issues that may limit the value of neuroscience to the study of group processes and relations. We then argue that social neuroscience indeed holds significant promise for understanding many social psychological phenomena, and we discuss this potential for the future.

\section{Historical relations between social psychology and neuroscience}

Over the past 50 years, there has been a systematic shift within social psychology from studying behavior at more molar levels of analysis to more molecular levels. In a stimulating analysis of trends in social psychology, Steiner (1974) asked in the title of his article, 'Whatever happened to the group in social psychology?' Social 
psychology, which was dominated by research in the United States, had systematically shifted its emphasis to more molecular units of analysis. Steiner noted that 'for a decade following World War II social psychologists tended to view the individual as an element in a larger system. Research on small groups prospered.... But by the 1960s social psychology had become much more individualistic.... [R] esearch was focused on intra-individual events or processes that mediate responses to social situations' (p. 94).

Soon after Steiner's paper, in the mid-1970s, this trend became even stronger, with even greater attention devoted to individual and intra-individual level processes. Social cognition became a dominant theme in social psychology. The social cognition movement borrowed many techniques (e.g. response time measures) from cognitive psychology and applied the general perspective and specific theories of cognitive psychology to study traditional social psychological processes. Gilbert (1999) explains, 'The social cognitive movement was characterized by ... its allegiance to the information processing metaphor, which suggested that mental phenomena are properly explained by describing a sequence of hypothetical operations and structures that might produce them' (p. 777). Once social psychologists became interested in such low-level, intra-individual phenomena as information processing, memory, and implicit cognition, more serious attention began to be paid by social psychologists to brain structure and function.

In recent years, thanks largely to advances in computational and methodological approaches for studying neural systems, the fields of neurobiology and psychology saw the emergence of neuroscience as an independent field bridging interests in a number of disciplines. The brain represented a fundamental area of common ground for both neurobiologists and psychologists, and neuroscience has produced many unique insights. However, these insights were limited in focus, and many of the phenomena that are so central to social psychology were excluded from consideration. Cacioppo et al.
(2007) observed, 'There have been important advances in our understanding of the links between mind, brain, and behavior over the past century, but it has been conventional to conceptualize individuals as somewhat isolated units of analysis .... To the extent that social factors were suspected of being relevant, their consideration would so complicate the study of brain and behavior that they were not a priority' (p. 100).

This state of affairs began to change in the 1990 s with the emergence of social neuroscience. Socialneuroscience is 'an interdisciplinary field devoted to understanding how biological systems implement social processes and behavior, capitalizing on biological concepts and methods to inform and refine theories of social processes and behavior, and using social and behavioral concepts and data to refine theories of neural organization and function' (Cacioppo et al., 2007, p. 100). Indeed, social neuroscience may be particularly promising precisely because it represents a convergence of research interests that have been pursued largely in parallel and with little conversation or cross-pollination.

While being supportive of this timely and important new interdisciplinary movement, in the present article we aim to take stock of the implications of neuroscience for social psychology. We believe that it is important to consider the problems as well as the promise of neuroscience, particularly for those areas of social psychology related to group processes and intergroup relations. Our focus will be on brain processes, with an emphasis on fMRI research to illustrate many of our points. We first offer a critique of the use of neuroimaging data for the study of group processes and intergroup relations. We then shift our analysis by highlighting what we see as some points of considerable promise of social neuroscience for advancing social psychological knowledge within the domain of intergroup psychology. Our appraisal is an intentionally critical (and perhaps controversial) one, aimed at encouraging a greater, albeit more critical, collaborative and integrative effort among the disciplines. 


\section{Concerns about a social neuroscience approach for social psychology}

There are many reasons to be concerned about the impact of neuroscience on social psychological research. In this section we consider theoretical, empirical, and pragmatic bases of concern.

\section{Theoretical perspectives on social behavior}

One general issue is that although neuroscience may be very useful to social psychology at some levels of analysis (e.g. social cognition), trying to reduce other types of complex social phenomena to specific brain structures and processes may not be helpful and may distract researchers from pursuing more molar explanations for social behavior. We are not the first to suggest this point. Harmon-Jones and Devine (2003) cautioned that 'some issues and phenomena examined by social psychologists may not be reducible to a neuroscience (and hence more molecular) level of analysis' (p. 590).

One of the unique aspects of social psychology, in general, and the study of intergroup relations, in particular, is the scope of its perspective (Pettigrew, 1988). Understanding intergroup relations involves recognition of structural, situational, individual, and intra-individual processes. Whereas intra-individual-, individual-, and situational-level processes may benefit directly from techniques in social neuroscience, the relevance of social neuroscience to structural theories of intergroup behavior is much less clear. For instance, intergroup inequities in power and influence between Whites and Blacks are perpetuated through institutional discrimination, in which laws, policies, and institutional practices favor Whites over Blacks in ways that are often subtle and unrecognized (Feagin, 2006). Structural forces have similarly been implicated in the maintenance of inequality across a number of other domains of group life (Jost, Burgess, \& Mosso, 2001; Sidanius \& Pratto, 1999). Social neuroscience may help illuminate intra-individual processes reflecting and contributing to intergroup bias, but such findings cannot supplant investigations at more macro-levels of analysis, such as the role of system-level forces in shaping intergroup relations. Moreover, too narrow a focus on intra-individual processes can distract social psychologists from the critical impact of more macro-level processes associated with social structure.

\section{Empirical perspectives}

Empirically, social neuroscience is seductive. It is able to convey a sense of knowledge in a powerful way. As social psychologists have long known, the authority and credibility of the source of a message substantially influences the impact of a message (Aronson, Turner, \& Carlsmith, 1963). Medicine and the biological sciences have traditionally been seen as more prestigious and authoritative than the social and behavioral sciences (Kanekar, 1990).

Moreover, the results of neuroscience studies, which are often concretely illustrated with brain images, are more effective, particularly for an audience beyond the profession, at communicating key findings than are the statistical analyses and means that are typically represented in social psychological research (Dovidio \& Gaertner, 2007). Indeed, a recent series of studies by Weisberg and colleagues (Weisberg, Keil, Goodstein, Rawson, \& Gray, 2008). Illustrates well what they describe as the 'seductive allure' of neuroscience data. When given brief descriptions of psychological phenomena followed by logically irrelevant neuroscience results or no neuroscience results, both naive adults and students in a neuroscience course judged that explanations with logically irrelevant neuroscience information were more satisfying than explanations without such information. Notably, this bias was found to be particularly strong when the information was coupled with a bad explanation; for novices and neuroscience students alike, neuroscience data seemed to mask otherwise salient logical inconsistencies in the arguments presented.

In their analysis of these findings, the authors argued that people may be more generally biased toward favoring a reductionist framework when confronted with explanatory information, adding: 'The mere mention of a lower level of analysis may have made the bad behavioral explanations seem connected to a larger explanatory system, 
and hence more insightful. If this is the case, other types of logically irrelevant information that tap into a general reductionist framework could encourage people to judge a wide variety of poor explanations as satisfying' (p. 476). The danger of such a reductionism bias is particularly evident when considering social neuroscientific findings that, by nature, present both lower and higher level (i.e. neural and behavioral) accounts within the same study. Such presentations may leave readers with the potentially false impression that they are extracting more 'scientific' information from the inclusion of lower level data. Minimally, such a bias may both reflect and promote a tendency to unduly privilege one level of analysis over another, the theoretical, methodological, and practical consequences of which we discuss in subsequent sections. As others have cogently argued (see Cacciopo et al., 2003), it is thus important that researchers and audiences alike hold neuroscience and behavioral data to the same statistical and interpretational standards.

The inherent allure of neuroscience data poses another more fundamental challenge to behavioral researchers. From the specific perspective of social psychology, neuroimaging results may sometimes add little new information beyond the insights that can be gleaned from purely behavioral data. In 2003, for instance, Richeson and Shelton published a study in Psychological Science, 'When Prejudice Does Not Pay: Effects of Interracial Contact on Executive Function'. This research, which investigated intergroup interactions, was conducted using traditional social psychological methods. White participants, who had previously been tested for level of implicit prejudice on the Implicit Association Test (IAT; Greenwald, McGhee, \& Schwartz, 1998), had a brief interaction with either a White or a Black confederate. After the interaction, the participants performed a Stroop (1935) Color-Naming task in which they were asked to responded to the text color in which a stimulus word appeared, independent of the semantic meaning of the word, with the reaction time to incompatible trials (e.g. the word 'yellow' in blue text) reflecting response inhibition, or 'executive attentional capacity'. The key prediction made by the researchers was that the cognitive demands of interracial interaction, as compared to intraracial interaction, would impair Whites' subsequent performance on the Stroop task.

The study was theoretically elegant, required only common laboratory equipment (a personal computer with a button-box interface), and produced supportive results. In addition, as expected, the interference on the Stroop task was greater for White participants higher in implicit prejudice. Further, in a subsequent study, Richeson, Trawalter, and Shelton (2005) replicated these results for Black subjects in interracial and intraracial interactions.

Around the same time, Richeson and colleagues (Richeson et al., 2003), published another paper, 'An fMRI Investigation of the Impact of Intererracial Contact Executive Function,' in Nature Neuroscience. This study employed sophisticated fMRI technology, but this technology required a fundamental change in procedure. Richeson et al. explain, 'Because it is not yet feasible to measure brain activity during actual face-to-face interaction, we used fMRI to assess neural activity in response to photographs of unfamiliar black faces as a proxy'. The results obtained were as predicted. Implicit prejudice predicted subsequent impaired performance on a Stroop task after viewing Black faces, and this effect was mediated by activity in the right dorsolateral prefrontal cortex, a brain region hypothesized to be critical to executive function. The authors concluded, 'These results are consistent with a resource depletion account of the temporary executive dysfunction seen in racially biased individuals after interracial contact' (p. 1323).

This is another elegant study with interesting results. However, the question we pose is this, from the perspective of social psychology, how informative is the information about mediation by right dorsolateral prefrontal cortex activation for understanding intergroup relations, particularly when pictures are substituted for actual interracial interaction? Passive viewing of faces can elicit a number of different psychological responses (e.g. efforts at controlling particular responses and/or anxious rumination about 
appearing prejudiced to the experimenters), and the nature of the response is difficult to determine without a behavioral task to validate the interpretation. We definitely feel that research of this type is valuable, and frequently cite these findings in our own research. We acknowledge that the fMRI results are in may ways titillating, and the findings may be very important from a neuroscience perspective, but do the expense of brain imaging and the necessary shift away from the mundane realism of actual interaction enhance the bottom-line conclusion (obtained with the classic Stroop procedure) of primary relevance to intergroup researchers that interracial interactions deplete the cognitive resources of both White and Black participants? There is probably no correct or consensual answer to this question, but it is one that we believe needs to be asked by researchers who study group processes and intergroup relations.

\section{Interpretations of social neuroscience findings}

Even when we answer the question we posed affirmatively, instantiating the incremental value of underlying brain activity for understanding particular questions about group processes and intergroup relations, social psychology has to be wary of the tendency to over-interpret social neuroscience findings because of unfamiliarity with the measures or enthusiasm to embrace convergent 'scientific' findings.

Again we will illustrate this with a particular example. As a result of the growing popularity of functional neuroimaging, many studies focused on implicit and explicit reactions to racial stimuli have utilized neuroimaging techniques (Eberhardt, 2005; Phelps \& Thomas, 2003) in concert with the IAT. The most popular target for neuroimaging studies looking for a neural basis for implicit attitudes is, by far, the amygdala. Many studies have investigated the neural response to viewing Black and White faces and performance on the IAT with a focus on changes in amygdala activation, and have begun to form a picture of the neural basis for implicit attitudes. A general conclusion often taken from this research is that amygdala activation is greater when people view members of another race than their own race, and that this activation is greater among people with more negative implicit racial attitudes (as measured by the IAT) (Dovidio, Kawakami, Smoak, \& Gaertner, in press); Wheeler \& Fiske, 2005).

An examination of the actual studies on which this conclusion is generally based reveals a less consistent empirical picture. In one of the first imaging studies to examine responses to viewing other-race faces (Hart et al., 2000), during the first presentation and scan, no differences in amygdala activation were found in response to racial ingroup and outgroup faces. During the second presentation and scan, participants generally responded with greater amygdala activation while viewing faces of the racial outgroup relative to the ingroup (White faces for Blacks, and Black faces for Whites), but this difference was the result of a decrease, or habituation, of the amygdala response to ingroup faces.

With respect to the relationship between implicit prejudice and amygdala activation, Phelps and colleagues (2000) found a correlation for White participants between amygdala activation while viewing unfamiliar Black-versus-White faces and IAT responses, but they did not observe this relationship when the faces shown were familiar. Cunningham, Raye and Johnson (2004) further investigated the relationship between implicit prejudice and amygdala activation to Whites' responses to Black and White faces presented subliminally (30 ms exposure followed by a mask) and supraliminally (525 ms exposure). For the subliminal presentation of faces, there was greater amygdala activation when viewing Black faces than White faces. As in Phelps et al. (2000), this activation was correlated with IAT performance. For the supraliminal presentation of faces, the procedure used in Phelps et al. (2000), there was no significant differential activation of the amygdala. Only after 'controlling for discrepancies between indirect and self-report measures' (p. 811) did the IAT correlate with differential Black-White amygdala activity.

In still another related experiment, Lieberman, Hariri, Jarcho, Eisenberger, and Bookheimer (2005) explored the amygdalar response to faces in both Black and White subjects. The authors 
report greater amygdala activation across both White and Black participants when viewing Black faces compared to Whites faces. The researchers reached two conclusions. First, although the amygdala might respond to both threat and unfamiliarity, it cannot be responding due to unfamiliarity in this case, as Black participants are most likely more familiar with other Black faces, and still show greater amygdala activation to Black faces. Second, the researchers proposed that the amygdala is reflecting cultural rather than individual patterns. That is, they posit that the amygdala reaction to faces is not based on an individual ingroup/outgroup basis, but rather on an approximation of the sum of the learned cultural messages about a given group.

These results are, collectively, interesting and potentially valuable. The problem lies not in the quality of research itself, but in oversimplified conclusions that people more distant from neuroscience often draw from research that is complex and technical. Moreover, it is often difficult for people outside of a field to remain current with rapid developments in the area. For instance, whereas prior research implicated the amygdala as predominantly a 'fear' module, activated in response to threatening stimuli, more recent studies suggest the amygdala may be responsive to any attention-worthy stimuli, negative or positive, and may have a broader function of perceptual vigilance (see Phelps, 2006). Furthermore, more recent neuroscientific work suggests that it may often be misleading to conceptualize neural responses as primarily localized in specific regions of the brain rather than considering the critical role of higher-order integrating pathways and connectivity systems in the brain. This may be a particular consideration for social neuroscience studies, which often seek to investigate multiple psychological processes operating concurrently, as in the case of affect regulation (see Ochsner, 2007).

Too narrow of a focus on intra-individual processes can also lead researchers to ignore other, relevant social psychological explanations for the data. The social context and experimental cues in the studies of amygdala activation and implicit prejudice we have described likely alerted participants to the racially sensitive nature of the research. As a consequence, participants, especially those who have racial biases, may be particularly vigilant for Blacks faces. It may be this heightened vigilance, rather than group-associated threat, that accounts for the correlation between implicit prejudice and amygdala activation. It is therefore important that social psychologists maintain a broad perspective rather than rush to judgment based on limited, and not always fully consistent, information. We caution that 'a little knowledge can be a dangerous thing'.

One may be tempted to ask whether the problem of oversimplified conclusions is not simply one inherent with any cross-disciplinary work, where relative nonexpertise in some domains may leave experts in another often reaching 'beyond the data'. From the social psychologist's perspective, what might be special about neuroimaging data, in particular, that might lead one to draw such conclusions? As others have cautioned (e.g. Ochsner, 2007), there is potential danger in drawing psychological inferences from functional neuroimaging data-invoking localized neural activity (or deactivations) as evidence of the invocation of particular psychological processes-and we briefly highlight one particular concern that social psychologists should consider when developing and interpreting neuroimaging studies.

Results of a recent meta-analytic investigation of neuroimaging findings suggest that neuroimaging data often suffer from low consistency and may be particularly susceptible to false positives, given the often hundreds of thousands of comparisons involved in each study and the need to maintain statistical power with small samples (Wager, Lindquist, \& Kaplan, 2007). Wager and colleagues estimated that as many as $10-20 \%$ of reported activations in published studies are false positives. With an ever growing body of findings and advancing statistical methods for analyzing such data in aggregated form, we suggest that such issues may be less a problem for neuroscience as it is for those in other disciplines tempted to use findings from individual imaging studies to support claims of psychological processes. 
As one example, considerable attention has recently been paid to exploring the functional neural architecture of affective response. A particular point of contention has been the relative absence of evidence for the localization of discrete emotional experience based on metaanalytic reviews (for a review, see Barrett \& Wager, 2006). Individual studies, however, have shown substantial variation in localization of emotional states, providing researchers with a veritable database, although as of yet unsupported meta-analytically, of emotion-neural activation correspondence from which to substantiate claims of specificity of emotional experience. This may be of particular importance in theories positing discrete systematic emotional experiences in the presence of particular outgroups. Whereas the behavioral data are convincing, one might consider the jury still out on neuroimaging data and avoid reliance on individual study findings to instantiate and advance intergroup theories of emotion.

\section{Practical considerations}

Science is not value- or context-free. Pragmatic issues are typically of concern. In this section we consider two additional issues relating to the potential impact of social neuroscience on social psychology. Neither argument has the strength of systematic empirical evidence, but the potential effects are tangible. Both arguments concern the expense of fMRI research.

Besides the expense of the fMRI equipment and its operation, access to the equipment can be quite costly (e.g. US $\$ 500$ or more per hour). Even beyond the financial constraints, many magnets are primarily reserved for clinical use, and time available for research is often quite limited. As a consequence of this restricted and costly access, researchers have less freedom to perform exploratory research, and when they do perform focused experiments, researchers often require a high level of certainty of achieving the predicted results before they initiate the study. A colleague who does fMRI research recently commented, 'Before I give someone access to the magnet, they have to show me good behavioral evidence for the hypotheses'. This is a reasonable requirement from a neuroscience perspective, but once the persuasive behavioral evidence has been obtained, from a social psychological perspective one might ask whether the neuroscience evidence is needed. Certainly, in many cases neuroscience data may provide additional information that could not be gleaned from a purely behavioral study. However, the fact that practical constraints frequently orient researchers more toward confirming existing social psychological theories and corroborating findings with neuroimaging data than developing new theories can limit the contribution of neuroscience to social psychology. Furthermore, the expenses associated with imaging research often place constraints on study designs, limiting the types of studies investigators can pursue. Most notably, this has led to an often necessary overreliance on within-subject designs for the use of smaller sample sizes and the incorporation of a more limited number of well-validated experimental paradigms. Indeed, the broad and varied nature of many social psychological studies may be seen as a particular strength of the field, particularly for investigations of social interaction.

Another practical issue related to the expense of fMRI research involves funding. Research using fMRI has captured the interest of government officials and funding agencies across the world. It is a wonderful tool, and more researchers are using it. Outside of psychology, neuroeconomics is a rapidly growing and valuable area of study with the potential to bring new insights into our understanding of intergroup processes (Knoch, Pascual-Leone, Meyer, Treyer, \& Fehr, 2006). We caution, however, that researchers, legislators, and funding agencies need to maintain a balance of support between behavioral (social science) research and medical, biological, and neuroscience research.

Besides the long-term importance of promoting new developments in all areas of science, there are immediate practical concerns as well. When the AIDS epidemic first broke out, there was strong advocacy by the medical community that virtually all the government funding be directed toward a medical solution. There was optimism that with sufficient resources AIDS could be cured or prevented through inoculation 
in just a few years. The US government chose more balanced funding.

It was a wise decision. Although medical research has made impressive strides with drug treatments that extend the lives of HIV-positive individuals and greatly improved their quality of life, now, many years later, there is still no cure. Ironically, without the funding that has supported behavioral interventions to promote safe sexual practices to limit the spread of HIV (Fisher, Fisher, Amico, \& Harmon, 2006), the medical advances in this area might have greatly increased the spread of AIDS. More people living normal lives with HIV would increase the likelihood that HIV could be transmitted to larger populations. The behavioral research and the interventions that have resulted have thus complemented the medical research in ways with invaluable benefits to individuals and society.

\section{Promise of social neuroscience for social psychology}

In the previous section, we presented a contrary view of the impact of social neuroscience on social psychology. We did so not simply to play the role of devil's advocate, but also out of some genuine concerns for the field and its future. In this section, we offer balance by highlighting the positive implications and reasons why social psychology should embrace social neuroscience. Paralleling the section on concerns, we highlight theoretical, empirical, and practical reasons, but in the reverse order, with practical considerations first.

\section{Practical considerations}

In the last section, we emphasized the question of what value neuroscience is to social psychology. Our analysis suggested that, at least at the present time, social neuroscience may often be of more scientific interest, both theoretically and empirically, to neuroscientists than it is to social psychologists, particularly those studying group processes and intergroup relations. Nevertheless, we contend that such a parochial view of social psychology is not in the field's long-term best interest.
Besides missed opportunities for funding, some of the most important and exciting new discoveries are at the boundaries of traditional disciplines and at mutlidisciplinary intersections. Prejudice is a good case study. Prejudice is influenced by processes at many different levels: cultural, historical, institutional, intergroup, interpersonal, and intra-individual. Moreover, these forces can operate separately or in concert, with processes at one level influencing processes at another level or with processes at different levels operating simultaneously to shape people's immediate behaviors.

For instance, both sociologists and social psychologists have long proposed that group competition and threat are fundamental processes in the development and maintenance of prejudice. The different disciplinary approaches have recently been integrated into more comprehensive theories, such as realistic group conflict theory (Bobo, 1999). In addition, whereas sociology's concern with competition for resources has informed social psychological theory of intergroup relations, social psychology's recognition of less tangible sources of group conflict, such as needs for collective esteem and reduction of uncertainty, has offered a different perspective on prejudice to sociology.

A group-level analysis of prejudice also helps to bridge research in social psychology to work in political science. Social dominance theory (Sidanius \& Pratto, 1999) emerged, in part, from investigations in the subdiscipline of political psychology, which has roots in both psychology and political science. According to social dominance theory, across cultures and history, complex human societies have organized themselves into group-based hierarchies. Dominant groups are motivated to maintain their privileged position, and they reinforce social stratification through structural factors (e.g. social or institutional policies) and psychological factors (e.g. the justification of prejudice). Thus, because of its function in reinforcing a dominant group's status, prejudice is ubiquitous, although its nature and its targets may differ from culture to culture and time to time.

An appreciation of the interplay of forces at different levels, not simply their independent 
effects, also promises significant new advances in developing a comprehensive understanding of prejudice. For example, although researchers gained many insights into within-individual processes of stereotyping and prejudice stemming from social-cognitive approaches that dominated social psychology in the 1970s and 1980s, the growing use of dyadic- and group-level analysis in more recent decades has brought with it new questions to the study of intergroup relations research. Among these have been new understandings of the experiential and perceptual dynamics of intergroup contact and a broader understanding of the maintenance of system-level forces, such as institutional discrimination (Sidanius \& Pratto, 1999).

Although the interdisciplinary connections in the study of the social psychology of prejudice have traditionally been directed toward more molar levels of analysis, they may now be orienting toward more molecular levels of analysis. Within social psychology, for example, a variety of different operationalizations (such as sex, race, and painting preference) have been used to study ingroup-outgroup relations. In addition, certain social categories, specifically sex, race, and age, have been identified as particularly salient dimensions that are encoded in an automatic and mandatory manner. Cosmides, Tooby, and Kurzban (2003) observed, 'Such results led some to propose that race, sex, and age are "primary" or "primitive" dimensions of person perception ... built into our cognitive architecture' (p. 174). Thus, the behavioral evidence has suggested that sexism and racism (and ageism) have common cognitive bases.

Neuroscience research, however, has revealed that sex and race activate different brain structures. Whereas racial categorization relates to general structures that have evolved for sensitivity to novelty or threat (amygdala) and neural systems that have evolved for tracking coalitions and alliances (Cosmides et al., 2003), sex and age are encoded in regions of the brain (frontocentral regions) that are not only different from the areas of activity associated with race but also distinct from those areas activated generally by visual analysis of faces (MouchetantRostaing \& Giard, 2003). Cosmides et al. (2003) argue that different patterns of brain activity associated with perceptions of race and gender are the consequence of very different evolutionary influences.

We note, however, that the data on this issue are far from conclusive; the Mouchetant-Rostaing and Giard (2003) research, for instance, did not assess subcortical (e.g. amygdala) activation, and amygdala activation cannot be taken as prima facie evidence for an innate, hard-wired basis for group perception, given that it responds to many other features of a particular context. Nevertheless, Cosmides et al.'s (2003) arguments, which have some tentative neuroscience support, are provocative and can stimulate further research exploring whether there are fundamental differences in the way the behaviorally primary categories of race, sex, and age are perceived and encoded. Taking advantage of the new ideas and techniques currently offered by social neuroscience thus opens new doors, not just to funding, but to scientific discovery.

\section{Empirical considerations}

Besides the broad promise of social neuroscience for future advances in social psychology, neuroscience can be particularly valuable by offering techniques to assess mechanisms that have been hypothesized in social psychological theory but are difficult to measure directly with conventional social psychological techniques (see also Harmon-Jones \& Devine, 2003). Indeed, there is concrete evidence of the value of incorporating lower level process measures, such as those used in social neuroscience and psychophysiological research, to understanding processes hypothesized to be central to intergroup relations. Although the present analysis has up to this point focused on measures of central nervous system activity (e.g. fMRI), we briefly turn to evidence examining peripheral nervous system activity to illustrate our point.

One of the key explanatory concepts in Social Identity Theory (Tajfel \& Turner, 1979) has been the construct of identity threat. Although a variety of forms of group threat, such as realistic and symbolic group threat, have proven amenable to direct self-report measures (Riek, Mania, \& Gaertner, 2006), there are few effective direct 
measures of social identity threat. Scheepers and Ellemers (2005) observed, 'Although the phenomenon has been proposed to account for a variety of more manifest responses to group status, social identity threat has not been actually assessed. Instead, threat has often been inferred from one of its assumed consequences, like derogation of an out-group' (p. 192). Instead, Scheepers and Ellemers applied a physiological measure, blood pressure, to study the occurrence of social identity threat. Blood pressure demonstrated a pattern of results consistent with predictions about experiences of identity threat derived from Social Identity Theory, whereas direct self-report measures of threat did not. Thus, psychophysiological responses may capture the essence of social identity threat in ways that self-reports can not (see also Gugliemi, 1999).

Although Social Identity Theory has emphasized the role of intergroup threat, which may be effectively indexed by cardiovascular response, other approaches to intergroup relations emphasize the role of cognitive representations of the self, others, and groups as a fundamental determinant of intergroup relations. SelfCategorization Theory (Turner, Hogg, Oakes, Reicher, \& Wethere II, 1987) posits that when social identity is salient, "people come to perceive themselves more as interchangeable exemplars of a social category' (Turner et al., 1987, p. 50). The Common Ingroup Identity Model (Gaertner \& Dovidio, 2000) hypothesizes that when people categorize others within a common collective identity the psychological distance is reduced between the self and others, and cognitive representations of the self and the ingroup become directly linked (Smith \& Henry, 1996). This emphasis on cognitive processes in intergroup relations draws attention to potential underlying neural processes.

Beyond the historical use of psychophysiological measures as alternatives to self-report, these theories of cognitive representations could benefit directly from neuroscience theory and techniques. In many current self-report measures of representations, such as the Inclusion of Others in the Self Scale (see Aron et al., 2004), in which greater overlap between two circles represents greater inclusion, it is not clear whether the overlap represents the self becoming identified with another or another becoming incorporated into the self. Although preliminary, recent neuroscience findings may offer some insight: Medial prefrontal cortical activity (Heatherton, Wyland, \& Macrae, 2006), specifically in the ventral and dorsal regions (D'Argembeau, Ruby, \& Collette, 2007), appears to relate uniquely to judgments of the self and self-referential processes, and the mentalizing of others, respectively (see also Harris \& Fiske, 2006; Johnson et al., 2006; Mitchell, Macrae, \& Banaji, 2006). The distinction about whether another person becomes incorporated within the self or becomes closer but remains distinct upon categorization within the same group is theoretically important in identity theories of intergroup relations. Social neuroscience may offer new ways of understanding and testing these effects empirically.

Additionally, neuroscience data can provide information to constrain theories in a way that behavioral data alone cannot. Imaging data are particularly valuable in detailing insights into how and when processes occur, helping to establish the similarity or dissociability of psychological mechanisms. Of particular interest to intergroup relations researchers, a consistent picture appears to be emerging regarding patterns of neural activation associated with more automatic versus controlled processing. Whereas controlled forms of social cognition have been consistently associated with activations in an identifiable system of brain structures (the 'C-system'; e.g. lateral prefrontal cortex), at present automatic forms have consistently been associated with activations in other structures (the 'X-system'; e.g. amygdala and lateral temporal cortex) (Lieberman, 2007). With regard to this pattern, Lieberman (2007) has recently suggested that this classic dichotomy may indeed reflect a 'core-processing' distinction within social cognitive neuroscience, that, in the future, might be used to identify automatic versus controlled processing in social psychological tasks without the need for subliminal presentations or cognitive load. The prospect of drawing such psychological inferences from 
functional imaging data brings with it the potential to substantiate theoretical claims and breed new insights into the recruitment and interplay of these and other 'core processes' suggested by neuroscience data, some of which may not yet be implicated in social psychological theory (see Lieberman, 2007, for an overview).

\section{Theoretical considerations}

The most significant contributions offered by social neuroscience are new theoretical perspectives. We discussed the general value of multidisciplinary perspectives in a previous section; in this section we consider specific applications. We offer two examples from the study of intergroup bias. One focuses on understanding the role of activation of intergroup biases and implicit attitudes. The other concerns the distinction between prejudice and stereotypes.

In 1996, Bargh published his highly influential chapter describing the activation of cognitive concepts, such as stereotypes and prejudice, as a 'cognitive monster' that pervasively, and perhaps inevitably, influences perceptions and action (see also Bargh \& Williams, 2006). It is important to consider, however, whether and how conscious processes and motivations might be able to inhibit or suppress implicit attitudes and stereotypes, once activated. Recent research from cognitive neuroscience offers some ideas about this possibility.

Although evidence of direct pathways is scant, there is some evidence that the prefrontal cortex, which is frequently implicated in controlled processing, can modulate amygdala activation (Grace \& Rosenkranz, 2002), including, as we described earlier, activation associated with racial bias (Phelps et al., 2000). Studies using fMRI have recently demonstrated that emotion reappraisal-reinterpreting emotioneliciting stimuli in a way that reduces emotional responding-recruits prefrontal systems implicated in other forms of cognitive control (e.g. working memory), and is dependent upon interactions between prefrontal and cingulate executive control systems and cortical and subcortical emotion-generative systems (Ochsner \&
Gross, 2005). In particular, reappraisal of negative emotion has been shown to activate dorsal anterior cingulate cortex and prefrontal cortex systems that support the selection and application of reappraisal strategies and modulate activity in low-level emotion processing systems, such as the amygdala or insula, in accordance with the goal of the appraisal (Ochsner, Bunge, Gross, \& Gabrieli, 2002; Ochsner \& Gross, 2005).

In addition, although not concretely showing the operation of a direct inhibiting pathway, research in social neuroscience has revealed that 'explicit and implicit evaluations (goodbad) involve somewhat different neural circuits' (Cunningham, Raye, \& Johnson, 2004, p. 1717). In particular, Cunningham, Raye et al. (2004) found that the mere exposure to an attitude object even when participants were not asked to evaluate the object (conditions of implicit evaluation), elicited amygdala activation, which was correlated with emotional intensity of evaluative response. In contrast, when the task involved explicit evaluation, activation occurred primarily in the areas in the frontal cortex rather than in the amygdala. Thus, 'hardwiring' in the brain suggests that it is possible to tame the cognitive monster through conscious cognitive control.

Moreover, social neuroscience can help promote theoretical development by identifying basic differences in neural activity that more clearly distinguish different types of processes, such as decision making and facial recognition, that may be less discernible at the level of overt behavior. For instance, Ermer, Guerin, Cosmides, Tooby, and Miller (2006) found evidence in an fMRI study that social exchange behavior may be regulated by a functionally specialized system associated with brain regions (anterior and posterior temporal cortex) that are not activated by other types of reasoning. Golby, Gabrieli, Chiao, and Eberhardt (2001) found evidence of differential activation in fusiform regions in response to same- and different-race face recognition that directly relates to the general behavioral finding that people tend to show superior memory for faces of people from their own race relative to another race. These insights are complementary to those 
of traditional mainstream social psychology, but they offer additional value by illuminating distinct dynamic underpinnings of intragroup and intergroup processes.

Social neuroscience has already contributed to theoretical refinements of traditionally fundamental social psychological concepts, such as prejudice and stereotyping. Conceptually, prejudice and stereotypes have been considered as distinct phenomena: prejudice is a general evaluative bias, whereas stereotypes are semantic associations (Dovidio, Brigham, Johnson, \& Gaertner, 1996). In practice, though, prejudice and stereotyping are often conflated as elements of intergroup bias, both practically, as often measured in our studies, as well as in our theorizing. Nevertheless, empirically, Dovidio et al. (1996) found in a meta-analytic review of the literature that individual differences in prejudice and stereotype endorsement were only modestly related $(r=.25)$.

From a social neuroscience perspective, the work of Amodio and colleagues (2007; Amodio \& Devine, 2006; Amodio, Devine, \& HarmonJones, 2007) offers theoretical insights into why prejudice and stereotyping are only moderately related and how they represent distinct processes. Of particular importance to their theorizing, Squire and Knowlton's (1994) neuroscience model of memory identifies two types of memory systems: declarative and nondeclarative. Declarative memory, which explicitly links facts and events, is associated with medial temporal lobe (hippocampus) activity. There are four elements of nondeclarative memory: (a) procedural, relating to skills and habits (associated with the striatum); (b) priming (neocortex); (c) simple classical conditioning, related to emotional responses (amygdala) and skeletalmusculature (cerebellum); and (d) nonassociative learning (reflex pathways). As an association between specific semantic concepts, stereotyping would theoretically fall into one type of nondeclarative memory, one related to priming. Prejudice, however, consisting of automatic emotional responses is related to another element of nondeclarative memory in Squire and Knowlton's framework, one reflecting classical conditioning.
Highlighting this neuroscience perspective, Amodio and Devine (2006) explained how prejudice and stereotyping may rely on fundamentally different neural mechanisms. Amodio and Devine wrote, 'An examination of anatomical and neurochemical connectivity of the amygdala and surrounding structures reveals strong direct links with neural regions associated with ... mobilizing fight or flight responses.... By contrast, ... semantic associations are likely embedded in distributed networks in association cortex and thus may influence social cognition by biasing higher order information processing, such as when inferring the beliefs and intentions of another person' (p. 653). In this case, an existing neuroscience model (and one that focuses on memory systems that have been wellsupported empirically within neuroscience; see Ochsner, 2007) provides new insights into an important distinction in social psychology, between prejudice and stereotyping: 'Although systems for affect- and semantic-based associations typically function in concert, and thus tend to appear blended in outward verbal and behavioral responses, a consideration of their distinct operations is critical for understanding the behavioral effects of implicit stereotyping and evaluation' (p. 653). In an elegant series of studies using only behavioral measures (response time measures, self-reports, and seating distance), Amodio and Devine demonstrated the cognitive and behavioral independence of prejudice and stereotyping.

\section{Conclusion}

There is a clearly burgeoning literature considering fundamental linkages between neuroscience and social psychology. The field of social neuroscience is rapidly evolving in its science and identity. Nevertheless, despite the exponential growth in this line of inquiry, publications on this topic remain sparse in mainstream social psychology journals. In addition, whereas neuroscience and the informationprocessing approach of social cognition appear complementary and well-suited to an integrated framework, the connection to higher-level concepts in the study of group process, identity, 
and intergroup relations is much less well established.

In this article, we presented a number of caveats about the value of social neuroscience for studying group-level phenomena. We believe that these are legitimate concerns, but they are not insurmountable. Moreover, we contend that there are significant benefits to having an even broader multidisciplinary orientation within social psychology, one that incorporates the perspectives, techniques, and knowledge of neuroscience. Although not all group phenomena can be reduced to neural substrates, social neuroscience needs to be recognized as providing an important complementary perspective with the potential to advance the study of intergroup phenomena by providing nonoverlapping insights one cannot glean from behavioral data alone.

The challenge for the near future is not for promoting social neuroscience research; social neuroscience is doing quite well on its own. The real challenge is finding ways for mainstream social psychology, and its publication arms, not simply to understand and appreciate social neuroscience but to bring it more to the center of the field. Situating social neuroscience nearer to the center of social psychology will help bring its ideas and insights to the consciousness of even researchers who have no interest in using fMRI, event related potential, or other psychophysiological techniques and stimulate creativity among those whose interests reside primarily at molar levels of analysis.

In the near term, the areas of social neuroscience and group processes are likely to continue to be somewhat strange bedfellows. We are still at the 'dating' stage, with appropriate wariness. Neuroscientists and traditionally trained social psychologists sometimes collaborate on problems of mutual interest. Sometimes these relationships are transient, other times more enduring. In the longer term, though, there is a newer generation of professionals who are being jointly trained in social psychology and neuroscience and who see the intimate connections across these areas at the most basic level of their theoretical analysis. This true integration of perspectives promises a long and healthy marriage that is balanced in its contribution to neuroscience and social psychology and offers genuinely comprehensive theories of complex social behavior.

\section{Acknowledgement}

Preparation of this article was supported by NSF Grant \# BCS-0613218 awarded to the first author.

\section{References}

Amodio, D. M. (2007, April). Implicit race bias: From brain to behavior. Colloquium presentation at the Department of Psychology, University of Connecticut, Storrs, CT.

Amodio, D. M., \& Devine, P. G. (2006). Stereotyping and evaluation in implicit race prejudice: Evidence for independent constructs and unique effects on behavior. Journal of Personality and Social Psychology, 91, 652-661.

Amodio, D. M., Devine, P. G., \& Harmon-Jones, E. (2007). Mechanisms for the regulation of intergroup responses: Insights from a social neuroscience approach. In E. Harmon-Jones \& P. Winkielman (Eds.), Social neuroscience: Integrating biological and psychological explanations of social behavior (pp. 353-375). New York: Guilford.

Aron, A., McLaughlin-Volpe, T., Mashek, D., Lewandowski, G., Wright, S. C., \& Aron, E. N. (2004). Including others in the self. In W. Stroebe \& M. Hewstone (Eds.), European review of social psychology (Vol. 15, pp. 101-132). Hove, E. Sussex, U.K.: Psychology Press.

Aronson, E., Turner, J.A., \& Carlsmith, J.M. (1963). Communicator credibility and communicator discrepancy as determinants of attitude change. Journal of Abnormal and Social Psychology, 67, 31-36.

Bargh J. A. (1996). Automaticity in social psychology. In A. W. Kruglanski (Ed.), Social psychology: Handbook of basic principles (pp. 169-183). New York: Guilford.

Bargh, J. A., \& Williams, E. L. (2006). The automaticity of social life. Current Directions in Psychological Science, 15, 1-4.

Barrett, L. F., \& Wager, T. (2006). The structure of emotion: Evidence from neuroimaging studies. Current Directions in Psychological Science, 15, 79-83.

Bobo, L. (1999). Prejudice as group position: Micro-foundations of a sociological approach to 
racism and race relations. Journal of Social Issues, $55,445-472$.

Cacioppo, J. T., Amaral, D. G., Blanchard, J. J., Cameron, J. L., Carter, C. S., Crews, D. et al. (2007). Social neuroscience: Progress and implications for mental health. Perspectives on Psychological Science, 2, 99-123.

Cacioppo, J. T., Berntson, G. G., Adolphs, R., Carter, C. S., Davidson, R. J., McClintock, K. et al. (Eds.). (2002). Foundations of social neuroscience. Cambridge, MA: MIT Press.

Cacioppo, J. T., Berntson, G. G., Lorig, T. S., Norris, C. J., Rickett, E., \& Nusbaum, H. (2003). Just because you're imaging the brain doesn't mean you can stop using your head: A primer and set of first principles. Journal of Personality and Social Psychology, 85, 650-661.

Cosmides, L., Tooby, J., \& Kurzban, R. (2003). Perceptions of race. Trends in Cognitive Science, 7, 173-179.

Cunningham, W. A., Johnson, M. K., Raye, C. L., Getenby, J. C., Gore, J. J., \& Banaji, M. R. (2004). Separable neural components in the processing of Black and White faces. Psychological Science, 15, 806-813.

Cunningham, W. A., Raye, C. L., \& Johnson, M. K. (2004). Implicit and explicit evaluation: fMRI correlates of valence, emotional intensity, and control in the processing of attitudes. Journal of Cognitive Neuroscience, 16, 1717-1729.

D'Argembeau, A., Ruby, P., \& Collette, F. (2007). Distinct regions of the medial prefrontal cortex are associated with self-referential processing and perspective taking. Journal of Cognitive Neuroscience, 19, 935-944.

Dovidio, J. F., Brigham, J. C., Johnson, B. T., \& Gaertner, S. L. (1996). Stereotyping, prejudice, and discrimination: Another look. In C. N. Macrae, M. Hewstone, \& C. Stangor (Eds.), Foundations of stereotypes and stereotyping (pp. 276-319). New York: Guilford.

Dovidio, J. F., \& Gaertner, S. L. (2007). Communicating basic behavioral science beyond the discipline: Reflections from social psychology. In M. Welch-Ross \& L. G. Fasig (Eds.), Handbook on communicating and disseminating behavioral science (pp. 93-110). Thousand Oaks, CA: Sage.

Dovidio, J. F., Kawakami, K., Smoak, N., \& Gaertner, S. L. (in press). The roles of implicit and explicit processes in contemporary prejudice. In R. Petty, R. Fazio, \& P. Brinol (Eds.), Implicit measures of attitudes. Mahwah, NJ: Erlbaum.
Eberhardt, J. L. (2005). Imaging race. American Psychologist, 60, 181-190.

Ermer, E., Guerin, S. A., Cosmides, L., Tooby, J., \& Miller, M. N. (2006). Theory of mind broad and narrow: Reasoning about social exchange engages ToM areas, precautionary reasoning does not. Social Neuroscience, 1, 196-209.

Feagin, J.R. (2006). Systematic racism: A theory of oppression. New York: Routledge.

Fisher, J. D., Fisher, W. A., Amico, K. R., \& Harmon, J. J. (2006). An information-motivationbehavioral skills model of adherence to antiretroviral therapy. Health Psychology, 25, 462-473.

Gaertner, S. L., \& Dovidio, J. F. (2000). Reducing intergroup bias: The common ingroup identity model. Philadelphia, PA: Psychology Press.

Gilbert, D. (1999). Social cognition. R. A. Wilson \& F. C. Keil (Eds.), The MIT encyclopedia of the cognitive sciences (pp. 777-778). Cambridge, MA: MIT Press.

Golby, A. J., Gabrielli, J. D. E., Chiao, J. Y., \& Eberhardt, J. L. (2001). Differential responses in the fusiform region to same-race and other-race faces. Nature Neuroscience, 4, 845-850.

Grace, A. A., \& Rosenkranz, J. A. (2002). Regulation of conditioned responses of basolateral amygdala neurons. Physiology and Behavior, 77, 489-493.

Greenwald, A., McGhee, D., \& Schwartz, J. (1998). Measuring individual differences in implicit cognition: The implicit association test. Journal of Personality and Social Psychology, 74, 1464-1480.

Gugliemi, R. S. (1999). Psychophysiological assessment of prejudice: Past research, current status, and future directions. Personality and Social Psychology Review, 3, 123-157.

Harmon-Jones, E., \& Devine, P. G. (2003). Introduction to the special section on social neuroscience: Promise and caveats. Journal of Personality and Social Psychology, 85, 589-593.

Harris, L., \& Fiske, S. T. (2006). Dehumanizing the lowest of the low: Neuroimaging responses to extreme outgroups. Psychological Science, 17 , 847-853.

Hart, A. J., Whalen, P. J., Shin, L. M., McInerney, S. C., Fischer, H., \& Rauch, S. L. (2000). Differential response in the human amygdala to racial outgroup vs ingroup face stimuli. Neuroreport, 11, 2351-2355.

Heatherton, T. F. (2004). Introduction to special issue on social cognitive neuroscience. Journal of Cognitive Neuroscience, 16, 1681-1682. 
Heatherton, T. F., Wyland, C. L., \& Macrae, C. N. (2006). Medial prefrontal activity differentiates self from close others. Social Cognitive and Affective Neuroscience, 1, 18-25.

Johnson, M. K., Raye, C. L., Mitchell, K. J., Touryan, S. R., Greene, E. J., \& Nolen-Hoeksema, S. (2006). Dissociating medial frontal and posterior cingulated activity during self-reflection. Social Cognitive and Affective Neuroscience, 1, 56-64.

Jost, J. T., Burgess, D., \& Mosso, C. O. (2001). Conflicts of legitimation among self, group, and system. In J. T. Jost \& B. Major (Eds.), The psychology of legitimacy (pp. 363-388). New York: Cambridge University Press.

Kanekar, S. (1990). Professional prestige as a function of discipline and gender. Journal of Applied Social Psychology, 20, 1026-1032.

Knoch, D., Pascual-Leone, A., Meyer, K., Treyer, V., \& Fehr, E. (2006). Diminishing reciprocal fairness by disrupting the right prefrontal cortex. Science, 314, 829-832.

Lieberman, M. D. (2007). Social cognitive neuroscience: A review of core

processes. Annual Review of Psychology, 58, 259-289.

Lieberman, M. D., Hariri, A., Jarcho, J. M., Eisenberger, N. I., \& Bookheimer, S. Y. (2005). An fMRI investigation of race-related amygdala activity in African American and CaucasianAmerican individuals. Nature Neuroscience, 8 , 720-722.

Mitchell, J. P., Macrae, C. N., \& Banaji, M. R. (2006). Dissociable medial prefrontal

contributions to judgments of similar and dissimilar others. Neuron, 50, 655-663.

Mouchetant-Rostaing, Y., \& Giard, M. H. (2003). Electrophysiological correlates of age and gender perception on human faces. Journal of Cognitive Neuroscience, 15, 900-910.

Ochsner, K. N. (2007). Social cognitive neuroscience: Historical development, core principles, and future promise. In A. Kruglanksi \& E. T. Higgins (Eds.), Social psychology: A handbook of basic principles (pp. 39-66). New York: Guilford.

Ochsner, K. N., Bunge, S. A., Gross, J. J., \& Gabrieli, J. D. (2002). Rethinking feelings: An fMRI study of the cognitive regulation of emotion. Journal of Cognitive Neuroscience, 14, 1215-1229.

Ochsner, K. N., \& Gross, J. J. (2005). The cognitive control of emotion. Trends in Cognitive Sciences, 9, 242-249.

Onorato, R. S., \& Turner, J. C. (2001). The 'I,' the 'me,' and the 'us': The psychological group and self-concept maintenance and change. In C. Sedikides \& M. B. Brewer (Eds.), Individual self, relational self, collective self (pp. 147-170). New York: Psychology Press.

Pettigrew, T. F. (1988). Influencing policy with social psychology. Journal of Social Issues, 44, 205-219.

Phelps, E. A., O’Conner, K. J., Cunningham, A. A., Funayama, E. S., Gatenby, J. C., Gore, J. C. et al. (2000). Performance on indirect measures of race evaluation predicts amygdale activation. Journal of Cognitive Neuroscience, 12, 729-738.

Phelps, E. A., \& Thomas, L. A. (2003). Race, behavior, and the brain: The role of neuroimaging in understanding complex social behaviors. Political Psychology, 24, 747-758.

Richeson, J. A., Baird, A. A., Gordon, H. L., Heatherton, T. F., Wyland, C. L., Trawalter, S. et al. (2003). An fMRI investigation of the imact of interracial contact on executive function. Nature Neuroscience, 6, 1323-1328.

Richeson, J. A., \& Shelton, J. N. (2003). When prejudice does not pay: Effects of interracial contact on executive function. Psychological Science, 14, 287-290.

Richeson, J. A., Trawalter, S., \& Shelton, J. N. (2005). African Americans' implicit racial attitudes and the depletion of executive function after interracial interactions. Social Cognition, 23, 336-352.

Riek, B. M., Mania, E. W., \& Gaertner, S. L. (2006). Intergroup threat and outgroup attitudes. Personality and Social Psychology Review, 10, 336-353.

Scheepers, D., \& Ellemers, N. (2005). When the pressure is up: The assessment of social identity threat in low and high status groups. Journal of Experimental Social Psychology, 41, 192-200.

Sidanius, J., \& Pratto, F. (1999). Social dominance: An intergroup theory of social hierarchy and oppression. New York: Cambridge University Press.

Smith, E. R., \& Henry, S. (1996). An in-group becomes part of the self: Response time evidence. Personality and Social Psychology Bulletin, 22, 635-642.

Squire, L. R., \& Knowlton, B. J. (1994). The organization of memory. In H. Morowitz \& J. L. Singer (Eds.), The mind, brain, and complex adaptive systems (pp. 63-97). Reading, MA: Addison-Wesley.

Steiner, I. D. (1974). Whatever happened to the group in social psychology? Journal of Experimental Social Psychology, 10, 94-108. 
Stroop, J. R. (1935). Studies of interference in serial verbal reactions. Journal of Experimental Psychology, 18, 643-662.

Tajfel, H., \& Turner, J. C. (1979). An integrative theory of intergroup conflict. In W. G. Austin \& S. Worchel (Eds.), The social psychology of intergroup relations (pp. 33-48). Monterey, CA: Brooks/Cole.

Turner, J. C. (1985). Social categorization and the self-concept: A social cognitive theory of group behavior. In E. J. Lawler (Ed.), Advances in group processer (Vol. 2, pp. 77-122). Greenwich, CT: JAI Press.

Turner, J. C., Hogg, M. A., Oakes, P. J., Reicher, S. D., \& Wetherell, M. S. (1987). Rediscovering the social group: A self-categorization theory. Oxford, UK: Basil Blackwell.

Wager, T. D., Lindquist, M., \& Kaplan, L. (2007). Meta-analysis of functional neuroimaging data: Current and future directions. Social, Cognitive, and Affective Neuroscience, 2, 150-158.

Weisberg, D. S., Keil, F. C., Goodstein, J., Rawson, E., \& Gray, J. (2008). The seductive allure of neuroscience explanations. Journal of Cognitive Neuroscience, 20, 470-477.

Wheeler, M. E., \& Fiske, S. T. (2005). Controlling racial prejudice: Social-cognitive goals affect amygdala and stereotype activation. Psychological Science, 16, 56-63.

\section{Biographical Notes}

JOHN F. DOVIDIO is professor of psychology at Yale University. His research interests are in stereotyping, prejudice, and discrimination; social power and nonverbal communication; and altruism and helping.

ADAM R. PEARSON is a doctoral student in the Social Psychology program at Yale University. He received his MA in Psychology from the University of Connecticut and a BS in Biology from Cornell University. His research interests include intergroup relations, social perception, emotion, and social power.

PATRICK ORR is currently pursuing his PhD in Psychology at Yale University. His research interests include hormonal effects on learning and memory, and biological influences on social behavior. 